\title{
Gender disparities in mortality from infectious diseases in Serbia, 1991-2014: a time of civil wars and global crisis
}

\author{
M. $\operatorname{ILIC}^{1 *}$ AND I. ILIC ${ }^{2}$ \\ ${ }^{1}$ Department of Epidemiology, Faculty of Medical Sciences, University of Kragujevac, Serbia \\ ${ }^{2}$ Faculty of Medical Sciences, University of Kragujevac, Serbia
}

Received 23 February 2016; Final revision 27 May 2016; Accepted 2 June 2016; first published online 22 June 2016

\section{SUMMARY}

Infectious diseases remain one of the leading causes of death worldwide. The aim of this descriptive epidemiological study was to analyse the trends in mortality from infectious diseases in Serbia (excluding the Autonomous Province of Kosovo \& Metohia) from 1991 to 2014 using joinpoint regression analysis. The mortality rates from infectious diseases were found to have increased markedly from 1991 to 1994 (+12.4\% per year), followed by a significant decline from 1994 to 2009 ( $-4 \cdot 6 \%$ per year) and then another increase from 2009 to $2014(+4 \cdot 3 \%$ per year). Throughout the study period, mortality rates were consistently higher in men than in women. Although a substantial decline was observed for young people of both sexes, no consistent pattern was evident for the middle-aged nor the elderly. Since 1991, septicaemia has emerged as a leading cause of infectious disease mortality, particularly in older men. The Yugoslav civil wars in the 1990s and the global financial crisis in 2008 corresponded with changes in the trends in mortality from infectious diseases in Serbia, with the elderly showing particular vulnerability during those time periods. Data presented in this study might be useful to improve control of infectious diseases in Serbia.

Key words: Infectious diseases, joinpoint analysis, mortality, trend.

\section{INTRODUCTION}

Infectious diseases remain a significant public health problem [1-3]. According to the World Health Organization (WHO) estimates from 2012 [1], infectious diseases caused an estimated 6.4 million deaths worldwide (representing about $11.5 \%$ of all deaths), down from 8.7 million deaths $(16.4 \%$ of the global death rate) in 2000. Infectious diseases were reported as the most common cause of death in low-income countries, accounting for nearly $2 \cdot 1$ million deaths

\footnotetext{
* Author for correspondence: Professor M. Ilic, MD, PhD, Faculty of Medical Sciences, University of Kragujevac, Department of Epidemiology, S. Markovica 69, Kragujevac 34000, Serbia. (Email: drmilenailic@yahoo.com)
}

each year and $\sim 28 \cdot 2 \%$ of all annual deaths in both sexes. In Europe, which encompasses countries with more advanced economies generally, deaths by infectious diseases accounted for only $2 \cdot 5 \%$ of all deaths (an estimated 234000 deaths). The majority (97.5\%) of deaths from infectious diseases occurred in developing countries, and infectious diseases were ranked first among causes of death therein. Mortality of infectious diseases was highest in Sub-Saharan Africa (considered the most vulnerable region, with infectious diseases accounting for $34.5 \%$ of all deaths in 2012), while the lowest was recorded in the European region ( $2.6 \%$ of all deaths in 2012).

The rates of mortality from infectious diseases have shown a considerable decreasing trend throughout the 20th century for developed countries, such as the 
United States, England \& Wales, Australia, Italy, and Spain [3-7]. Moreover, the decreases were more marked in the young population ( $<24$ years) $[1,3,4]$. Studies demonstrated that the decreases in infectious disease mortality were linked to development of a country's infrastructure, including urbanization and improvements in sanitation, living conditions and nutrition as well as in healthcare, especially when vaccines and antimicrobial drugs were applied in clinical practice; increased funding of public health initiatives at the international level and implementation of effective global surveillance and response systems were also shown to have played a significant role, allowing for better control and eradication of a growing number of infectious diseases [2, 3].

The overall decrease in infectious disease mortality in developing countries since World War II led to a general perception of this problem as a minor threat [2]. However, the emergence of new infections, such as HIV/AIDS, hepatitis C, SARS and variant Creutzfeldt-Jakob disease, and the re-emergence of old diseases, such as tuberculosis and cholera, have underscored the importance of ongoing disease prevention through continual surveillance and control [8-10]. The emergence of HIV/AIDS, in particular, and its associated illnesses interrupted the progressive decreasing trend and contributed largely to an increase in mortality rates from infectious diseases in the 1990s [3, 8]. The continuous threats to human health related to infectious diseases may be correlated to ecological and climate changes, travel and trade, human behaviour, microbial adaptation and multiresistance, and host immunity [9]. Although the impact of the global financial crisis, which began in 2007, on infectious disease mortality still remains unclear, shifts in the epidemic profiles of infectious diseases were noted in many countries [11, 12].

Serbia is a small country in southeast Europe; in addition to civil wars, sanctions and bombing, democratic socioeconomic changes and financial crisis marked its socio-political landscape at the beginning of the 21 st century. To date, the epidemiological studies on infectious diseases in Serbia have assessed patterns within only focused geographical regions of the country [13]. The purpose of our study, therefore, was to determine the epidemiological characteristics of mortality rates of infectious diseases in the entire country of Serbia within the recent decades (19912014), representing a time-frame of civil wars and global crisis; understanding the trends in these mortality rates, as related to demographic parameters and principal causes, can help to improve control of infectious diseases in Serbia.

\section{MATERIALS AND METHODS}

\section{Study design}

For this descriptive epidemiological study, we assessed the annual underlying cause of death data (see below) from Serbia, excluding the Autonomous Province of Kosovo \& Metohia, to describe trends in mortality from infectious diseases for the period 1991-2014.

\section{Data sources}

Data on persons who died of infectious diseases [International Classification of Diseases revision 9 (ICD-9) codes 000-139 and revision 10 (ICD-10) codes A00-B99] were obtained from the Statistical Office of the Republic of Serbia (unpublished data); the data were classified using ICD-9 from 1991 to 1996, and from 1997 onwards using ICD-10. Mortality trends of tuberculosis (ICD-9: 010-018; ICD-10: A15-A19) and septicaemia (ICD-9: 038; ICD-10: A40-A41) were assessed separately. Additionally, overall mortality (mortality from all causes of death, ICD-9: 000-999; ICD-10: A00-T98) was assessed.

The study population comprised the entire population of the Republic of Serbia, during the period 1991-2014. Data were not available for the Autonomous Province of Kosovo \& Metohia, which declared itself independent in 2008; accordingly, the population of this region was not available for the study period.

Data on the number and composition of the Serbian population $(\sim 7.5$ million inhabitants) by age and sex were obtained from the 1991, 2002 and 2011 censuses [14]. During the study period, Serbia had the largest populations (nearly 500000 persons) of internally displaced persons (from Kosovo \& Metohia) and refugees (from the former Socialist Federal Republic of Yugoslavia) of all European countries, and data for these people were included in the overall analysis of the study since it could not be specified for segregation as a special contingent.

\section{Ethical considerations}

This study was approved by the Ethics Committee of the Faculty of Medical Sciences at the University of Kragujevac (ref. no. 01-1176). 


\section{Statistical analysis}

Three types of death rates were calculated: crude, specific (age- and sex-specific) and age-standardized (expressed per 100000 persons). Age-specific mortality rates were calculated for all ages and within age groups $(0-4,5-19,20-49,50-64, \geqslant 65$ years). Category standardization was performed by direct method, with 'European population' used as the standard population and age stratified by 5 -year intervals.

Mortality trends from infectious diseases were assessed using joinpoint regression analysis (Joinpoint Regression Program, v. 4·0·4-May 2013, available through the Surveillance Research Program of the US National Cancer Institute). The joinpoint analysis software detected occurrences of statistically significant changes (joinpoints) and determined the trends between joinpoints. Permutation tests were performed to identify the best-fitting combination of line segments and joinpoints [15]. The bivariables were sex and age group. The results are presented as straight lines connected at change points, on a log scale, and the trends in annual age-standardized mortality rates (ASRs) are characterized by an annual percentage change (APC) between successive change points. All estimates are presented with 95\% confidence intervals (CIs) [16]. Disparities in mortality trends according to sex and age were tested by comparability testing [17], which determined whether the two regression mean functions were identical (test of coincidence) or parallel (test of parallelism). $P<0 \cdot 05$ was considered statistically significant for all tests.

\section{RESULTS}

Infectious diseases accounted for $0.5 \%$ of total deaths in Serbia during the study period. Nearly 13000 (male to female ratio $1 \cdot 6: 1$ ) infectious disease deaths were recorded, with the average annual ASR being 6.0/ 100000 inhabitants (Table 1). The mortality rates from infectious diseases were twofold higher in men $(8 \cdot 2 / 100000)$ than in women $(4 \cdot 1 / 100000)$, and the average ASR for overall mortality was higher in men $(1285 \cdot 3 / 100000)$ than in women $(894 \cdot 6 / 100000)$.

The mortality rates from infectious diseases showed marked increases from 1991 to 1994 (+12.4\% per year) and significant decreases from 1994 to 2009 ( $-4 \cdot 6 \%$ per year) followed by renewed increases from 2009 to 2014 $(+4 \cdot 3 \%$ per year) (Fig. 1). However, the trend in overall mortality showed a significant decrease over
Table 1. Infectious diseases and overall mortality in Serbia, 1991-2014; specified infectious diseases as a proportion of all causes of deaths

\begin{tabular}{|c|c|c|c|c|c|}
\hline \multirow[b]{2}{*}{ Year } & \multicolumn{2}{|c|}{$\begin{array}{l}\text { Infectious } \\
\text { diseases }\end{array}$} & \multirow{2}{*}{$\begin{array}{l}\% \text { of all } \\
\text { causes } \\
\text { of deaths }\end{array}$} & \multicolumn{2}{|c|}{$\begin{array}{l}\text { All causes of } \\
\text { deaths }\end{array}$} \\
\hline & No. & ASR & & No. & ASR \\
\hline 1991 & 484 & $6 \cdot 0$ & 0.54 & 89072 & $1129 \cdot 9$ \\
\hline 1992 & 550 & $6 \cdot 7$ & 0.59 & 93475 & $1179 \cdot 0$ \\
\hline 1993 & 610 & $7 \cdot 9$ & $0 \cdot 64$ & 95121 & $1190 \cdot 0$ \\
\hline 1994 & 648 & $8 \cdot 1$ & $0 \cdot 70$ & 93011 & $1145 \cdot 9$ \\
\hline 1995 & 614 & $7 \cdot 7$ & $0 \cdot 65$ & 93933 & $1137 \cdot 3$ \\
\hline 1996 & 725 & $8 \cdot 7$ & $0 \cdot 74$ & 98370 & $1174 \cdot 8$ \\
\hline 1997 & 618 & $7 \cdot 3$ & 0.63 & 98068 & $1157 \cdot 3$ \\
\hline 1998 & 576 & $6 \cdot 7$ & 0.58 & 99376 & $1160 \cdot 2$ \\
\hline 1999 & 565 & $6 \cdot 4$ & $0 \cdot 56$ & 101444 & $1161 \cdot 3$ \\
\hline 2000 & 577 & $6 \cdot 7$ & $0 \cdot 55$ & 104042 & $1173 \cdot 6$ \\
\hline 2001 & 512 & $5 \cdot 8$ & $0 \cdot 52$ & 99008 & $1100 \cdot 9$ \\
\hline 2002 & 540 & $5 \cdot 9$ & 0.53 & 102785 & $1136 \cdot 1$ \\
\hline 2003 & 559 & $6 \cdot 1$ & $0 \cdot 54$ & 103946 & $1130 \cdot 4$ \\
\hline 2004 & 516 & $5 \cdot 6$ & $0 \cdot 49$ & 104320 & $1099 \cdot 6$ \\
\hline 2005 & 546 & $5 \cdot 9$ & $0 \cdot 51$ & 106771 & $1092 \cdot 8$ \\
\hline 2006 & 450 & $4 \cdot 7$ & $0 \cdot 44$ & 102884 & $1025 \cdot 6$ \\
\hline 2007 & 435 & $4 \cdot 5$ & $0 \cdot 42$ & 102805 & $998 \cdot 9$ \\
\hline 2008 & 394 & $4 \cdot 0$ & $0 \cdot 38$ & 102711 & $976 \cdot 3$ \\
\hline 2009 & 412 & $4 \cdot 2$ & $0 \cdot 40$ & 104000 & $970 \cdot 6$ \\
\hline 2010 & 441 & $4 \cdot 5$ & $0 \cdot 43$ & 103211 & $947 \cdot 4$ \\
\hline 2011 & 438 & $4 \cdot 4$ & $0 \cdot 43$ & 102935 & $929 \cdot 7$ \\
\hline 2012 & 454 & $4 \cdot 4$ & $0 \cdot 44$ & 102400 & $928 \cdot 5$ \\
\hline 2013 & 583 & $5 \cdot 4$ & $0 \cdot 58$ & 100300 & $894 \cdot 5$ \\
\hline 2014 & 555 & $5 \cdot 2$ & $0 \cdot 55$ & 101247 & $887 \cdot 1$ \\
\hline Overall & 12802 & $6 \cdot 0$ & 0.53 & 2405235 & $1072 \cdot 0$ \\
\hline
\end{tabular}

$\overline{\text { ASR, Age standardized rate (using European standard }}$ population, per 100000 ).

the entire study period ( $-1 \cdot 3 \%$ per year). For the overall analysis of 1991-2014 only one joinpoint was detected, representing a non-significant change, showing a small increase $(+0 \cdot 1 \%$ per year $)$ from 1991 to 2000 , followed by a significant decrease $(-2 \cdot 0 \%$ per year from 2000 onwards). The mortality trends from infectious diseases and overall mortality in Serbia differed significantly (i.e. the final selected model rejected parallelism, $P<0.05)$.

Men showed a non-significant increase for infectious disease mortality during the period 1991-1993, which was followed by a significant decrease from 1993 to 2005 ( $-2 \cdot 8 \%$ per year), a non-significant decrease from 2005 to 2008 , and a steady increase from 2008 onwards $(+3 \cdot 6 \%$ per year) (Fig. 2$)$. The trend in overall mortality for men showed significant decrease over the entire study period $(-1 \cdot 3 \%$ per year); only one joinpoint was detected, representing a non-significant 


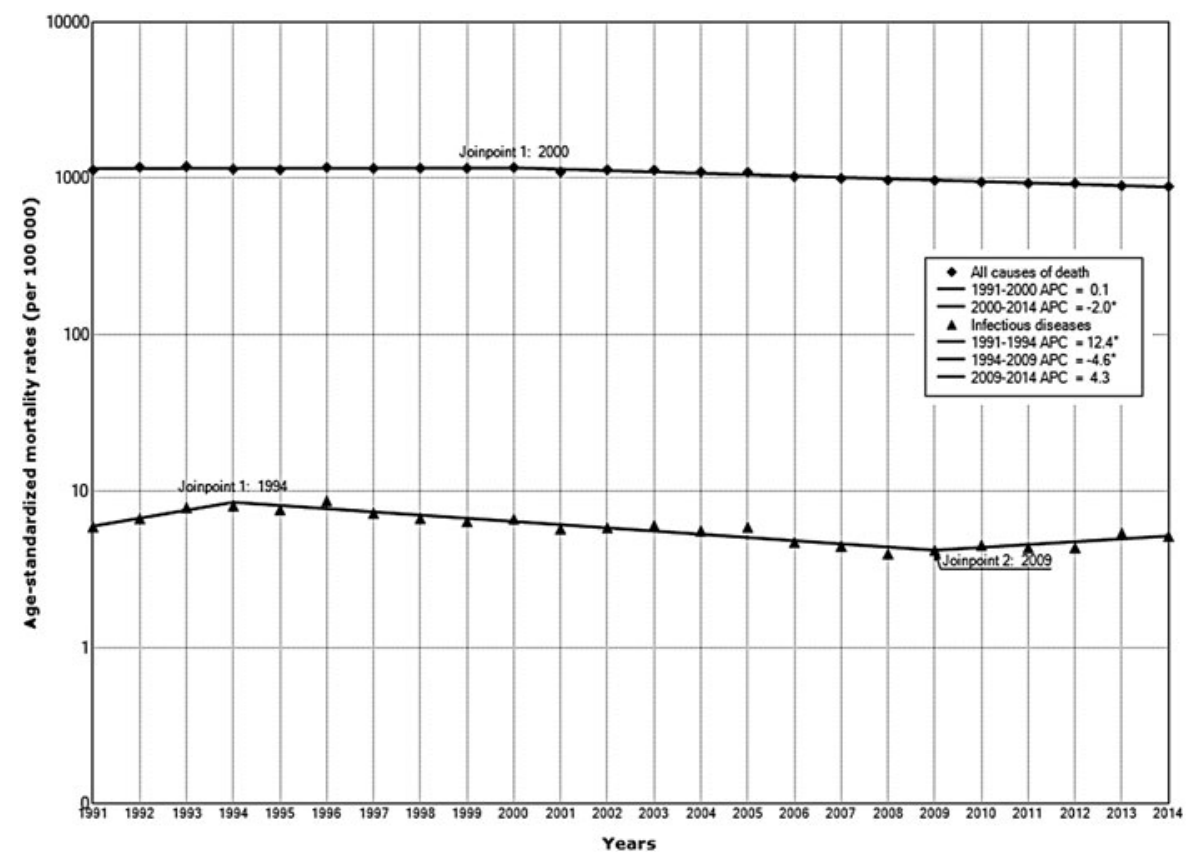

Fig. 1. Mortality from infectious disease and overall mortality in Serbia, 1991-2014: a joinpoint regression analysis (using logarithmic scale). All causes of death (1 joinpoint) vs. infectious diseases (2 joinpoints). ${ }^{*}$ Statistically significant trend; APC, annual percent change.

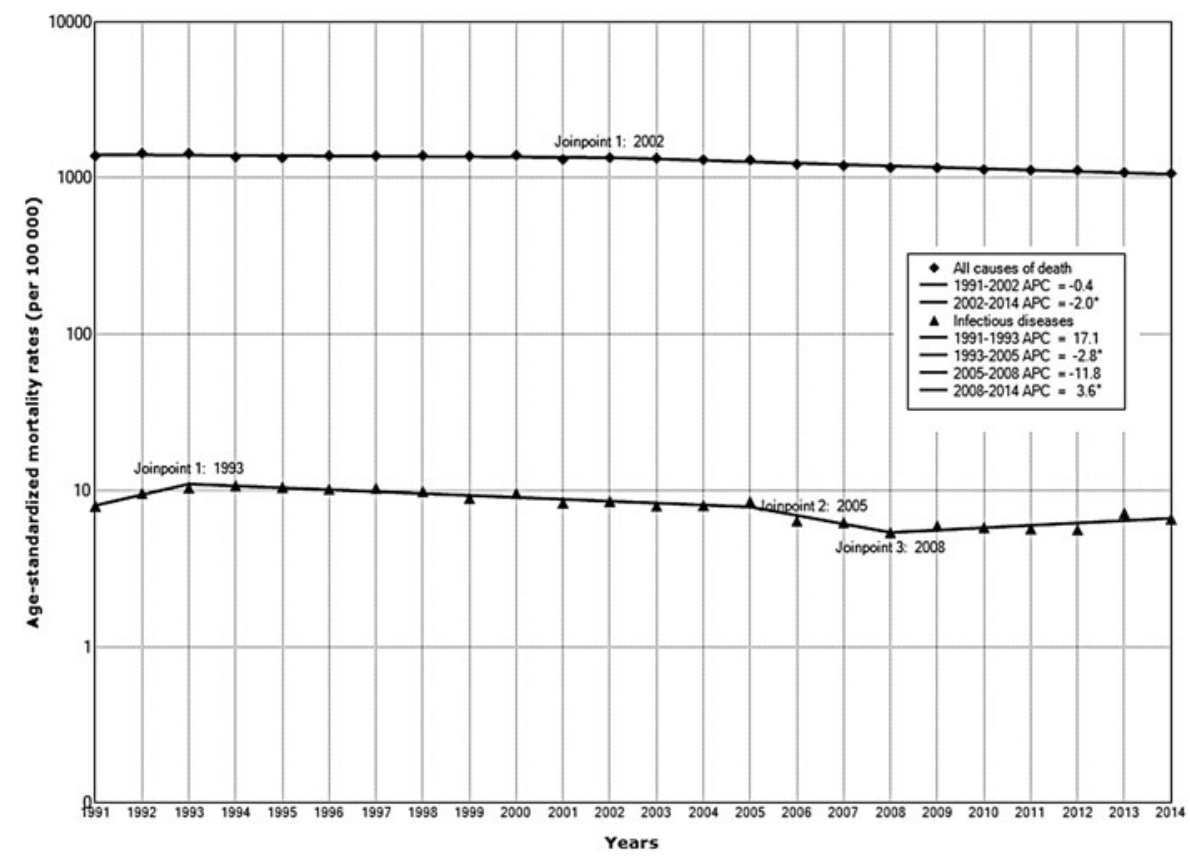

Fig. 2. Mortality from infectious diseases and overall mortality in men in Serbia, 1991-2014: a joinpoint regression analysis (using logarithmic scale). All causes of death (1 joinpoint) vs. infectious diseases (3 joinpoints). * Statistically significant trend; APC, annual percent change.

change, with a small decrease from 1991 to 2002 ( $-0.4 \%$ per year), followed by a significant decrease from 2002 onwards $(-2 \cdot 0 \%$ per year). The mortality trends from infectious diseases and overall mortality for men in Serbia differed significantly (i.e. the final selected model rejected parallelism, $P<0 \cdot 05)$. 


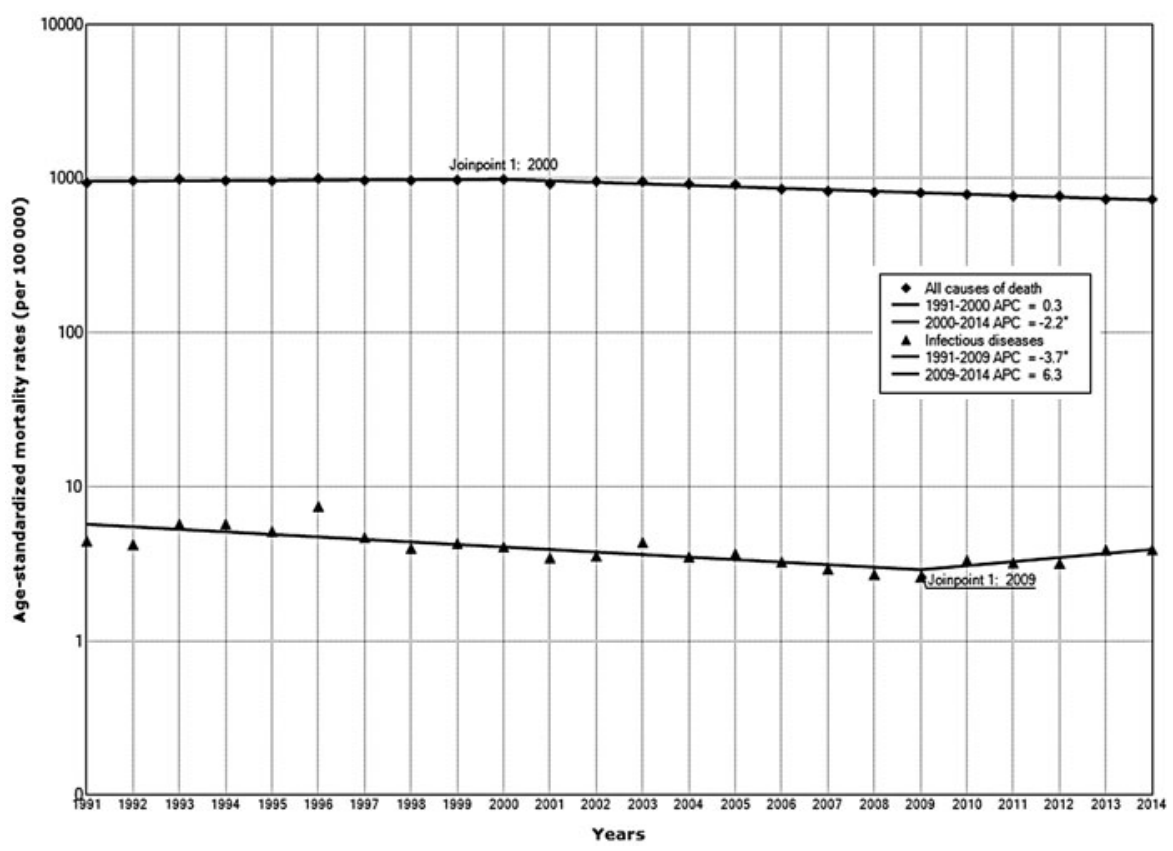

Fig. 3. Mortality from infectious diseases and overall mortality in women in Serbia, 1991-2014: a joinpoint regression analysis (using logarithmic scale). All causes of death (1 joinpoint) vs. infectious diseases (1 joinpoint). * Statistically significant trend; APC, annual percent change.

In women, infectious disease mortality decreased significantly from 1991 to 2009 ( $-3.7 \%$ per year), but then increased non-significantly from 2009 onwards (Fig. 3). The trend in overall mortality for women showed significant decrease over the entire study period $(-1 \cdot 3 \%$ per year); one joinpoint was detected, representing a non-significant change, with a small increase from 1991 to $2000(+0 \cdot 3 \%$ per year), followed by a significant decrease from 2000 onwards ( $-2 \cdot 2 \%$ per year). The mortality trends from infectious diseases and overall mortality for women in Serbia differed significantly (i.e. the final selected model rejected parallelism, $P<0 \cdot 05$ ).

When stratified by age group and sex, the rates of infectious disease mortality were higher in men than in women for all age groups (Table 2). Although there was a trend of substantial decline over time for young people of both sexes, no consistent pattern was evident for the middle aged and the elderly. In males aged 2049 years, the mortality rates significantly increased from 1991 to $1998(+7 \cdot 4 \%$ per year), and then significantly decreased from 1998 to $2014(-5 \cdot 2 \%$ per year). In males aged 50-64 years, the mortality rates increased from 1991 to 2000 and then showed a significant decline until 2011 ( $-4 \cdot 6 \%$ per year) followed by a sharp increase until 2014. In the oldest group of males ( $\geqslant 65$ years), the mortality rates showed a non-significant increase from 1991 to 1996 that was followed by a significant decrease from 1996 to 2009 ( $-4 \cdot 3 \%$ per year) followed by a rapid increase from 2009 onwards ( $+8.9 \%$ per year). In females aged 20-49 years, mortality increased non-significantly from 1991 to 1997, but then significantly and consistently decreased from 1997 onwards (-6.3\% per year). Middle-aged females (50-64 years) showed a significant declining trend in mortality $(-1.9 \%$ per year) over the entire study period, while elderly females ( $\geqslant 65$ years) showed a stable trend over the entire study period. Comparability testing indicated that mortality trends from infectious diseases in men aged $\geqslant 20$ years differed significantly from trends in the other age groups (i.e. the final selected model rejected parallelism, $P<0 \cdot 05$ ).

The most frequent causes of death in both sexes were tuberculosis and septicaemia, accounting for $72 \%$ of all infectious disease deaths (9204/12 802) (Table 3). The proportional contribution of intestinal infectious diseases, viral hepatitis and HIV to total infectious disease mortality were nearly equal, amounting to a total of $\sim 20 \%$.

Mortality trends from tuberculosis and septicaemia differed significantly. The trend of mortality from tuberculosis showed significant decrease over the entire study period ( $-6 \cdot 4 \%$ per year), while the corresponding trend of mortality from septicaemia showed an overall nonsignificant slight decrease $(-0 \cdot 8 \%$ per year) (Fig 4$)$. A significantly increasing trend was observed only for the 
Table 2. Joinpoint analysis: trends in age-specific mortality rates (per 100000 persons) from infectious diseases, men and women in Serbia, 1991-2014

\begin{tabular}{|c|c|c|c|c|}
\hline $\begin{array}{l}\text { Age, } \\
\text { years }\end{array}$ & $\begin{array}{l}\text { Average } \\
\text { annual } \\
\text { age-specific } \\
\text { rates }\end{array}$ & Period & APC & $95 \% \mathrm{CI}$ \\
\hline \multicolumn{5}{|l|}{ Men } \\
\hline $0-4$ & 6.99 & 1991-2014 & $-12 \cdot 4 *$ & $-16 \cdot 0$ to $-8 \cdot 6$ \\
\hline $5-19$ & $0 \cdot 52$ & 1991-2014 & $-4 \cdot 4 *$ & $-6 \cdot 8$ to -1.9 \\
\hline \multirow[t]{2}{*}{$20-49$} & $4 \cdot 02$ & $1991-1998$ & $+7 \cdot 4^{*}$ & $+0 \cdot 3$ to +14.9 \\
\hline & & 1998-2014 & $-5 \cdot 2 *$ & $-7 \cdot 2$ to $-3 \cdot 2$ \\
\hline \multirow[t]{3}{*}{$50-64$} & $13 \cdot 29$ & $1991-2000$ & $+0 \cdot 5$ & $-2 \cdot 1$ to $+3 \cdot 2$ \\
\hline & & 2000-2011 & $-4 \cdot 6^{*}$ & $-6 \cdot 7$ to $-2 \cdot 4$ \\
\hline & & 2011-2014 & $+12 \cdot 2$ & $-3 \cdot 0$ to $+29 \cdot 7$ \\
\hline \multirow[t]{3}{*}{$\geqslant 65$} & $35 \cdot 74$ & $1991-1996$ & $+6 \cdot 4$ & -1.0 to +14.3 \\
\hline & & 1996-2009 & $-4 \cdot 3 *$ & $-6 \cdot 1$ to $-2 \cdot 5$ \\
\hline & & 2009-2014 & $+8 \cdot 9^{*}$ & $+1 \cdot 3$ to $+17 \cdot 0$ \\
\hline \multicolumn{5}{|l|}{ Women } \\
\hline $0-4$ & $6 \cdot 24$ & 1991-2014 & $-12 \cdot 0^{*}$ & -16.0 to -7.9 \\
\hline $5-19$ & $0 \cdot 51$ & 1991-2014 & $-4 \cdot 6^{*}$ & $-8 \cdot 1$ to $-1 \cdot 1$ \\
\hline \multirow[t]{2}{*}{$20-49$} & $1 \cdot 69$ & 1991-1997 & $+9 \cdot 9$ & $-6 \cdot 7$ to $+29 \cdot 6$ \\
\hline & & 1997-2014 & $-6 \cdot 3 *$ & $-9 \cdot 5$ to $-3 \cdot 1$ \\
\hline $50-64$ & $5 \cdot 00$ & $1991-2014$ & $-1.9 *$ & $-3 \cdot 1$ to -0.6 \\
\hline$\geqslant 65$ & $20 \cdot 91$ & 1991-2014 & $0 \cdot 0$ & $-1 \cdot 2$ to $+1 \cdot 2$ \\
\hline
\end{tabular}

APC, Annual percent change; CI, confidence interval.

* Statistically significant trend.

rates of mortality from septicaemia from 1991 to 1995 $(+29 \cdot 3 \%$ per year); the increasing trend observed after 2009 fell below that threshold of statistical significance.

Trends in ASRs for mortality from tuberculosis and septicaemia showed a similar pattern in men and women (Table 4). Since 1991, all age groups, regardless of sex, showed a significant decrease in rates of mortality from tuberculosis. A trend of significant increases was shown for mortality from septicaemia for nearly all people aged $\geqslant 20$ years, regardless of sex, starting in 1991, with the notable exception of women aged between 20 and 49 years who showed a significant decrease throughout the entire study period. Moreover, a trend of decline in mortality rates from septicaemia was identified in nearly all age groups for both sexes from 1995 onwards, with the exception of elderly men who showed a significant increase starting in 2008 and continuing $(+19 \cdot 1 \%$ per year, $95 \%$ CI $3 \cdot 1-37 \cdot 3)$.

\section{DISCUSSION}

The present study describes temporal trends of mortality from infectious diseases in the Serbian population during the last two decades. A decreasing trend was present in most of the age groups regardless of sex, but it was more pronounced in women than in men. The sex gap in mortality rates from infectious diseases in persons aged $\geqslant 65$ years has become more pronounced in recent years, and this change is attributable mainly to the rise in septicaemia deaths in men. The observed significant decrease of mortality in younger age groups, in both sexes, could represent a promising future for the public health of Serbia with regard to infectious diseases.

Infectious diseases remain a relatively modest cause of death in the European region, even though there are substantial differences in mortality rates between the countries encompassed within. According to the most recent data available for the European region (mostly representing up to 2012), the highest mortality rates from infectious diseases in both sexes involve the Eastern European countries of Ukraine (28.8/100 000 persons) and the Russian Federation (21.8/100 000 persons), in addition to Israel (24.9/100 000 persons), while intermediate rates were reported in Belgium (13.0/100 000 persons) and Germany (11.3/100 000 persons) with the lowest rates reported in Finland $(3 \cdot 2 / 100000$ persons) [18]. In men, the highest rates 
Table 3. Infectious disease mortality in Serbia, 1991-2014; selected most common infectious diseases - number of deaths (age standardized rate, using European standard population, per 100 000)

\begin{tabular}{|c|c|c|c|c|c|}
\hline Year & Tuberculosis & Septicaemia & $\begin{array}{l}\text { Intestinal } \\
\text { infectious } \\
\text { diseases }\end{array}$ & $\begin{array}{l}\text { Viral } \\
\text { hepatitis }\end{array}$ & $\begin{array}{l}\text { HIV } \\
\text { disease }\end{array}$ \\
\hline 1991 & $298(3 \cdot 5)$ & $76(1 \cdot 0)$ & $35(0 \cdot 6)$ & $12(0 \cdot 1)$ & $0(0 \cdot 0)$ \\
\hline 1992 & $365(4 \cdot 2)$ & $73(1 \cdot 0)$ & $30(0 \cdot 5)$ & $16(0 \cdot 2)$ & $2(0 \cdot 0)$ \\
\hline 1993 & $347(4 \cdot 0)$ & $127(1 \cdot 8)$ & $59(1 \cdot 0)$ & $9(0 \cdot 1)$ & $2(0 \cdot 0)$ \\
\hline 1994 & $366(4 \cdot 2)$ & $164(2 \cdot 2)$ & $50(0 \cdot 9)$ & $15(0 \cdot 2)$ & $1(0 \cdot 0)$ \\
\hline 1995 & $321(3 \cdot 6)$ & $179(2 \cdot 4)$ & $49(0 \cdot 9)$ & $20(0 \cdot 2)$ & $6(0 \cdot 1)$ \\
\hline 1996 & $334(3 \cdot 7)$ & $242(3 \cdot 1)$ & $45(0 \cdot 8)$ & $16(0 \cdot 2)$ & $11(0 \cdot 1)$ \\
\hline 1997 & $284(3 \cdot 1)$ & $169(2 \cdot 1)$ & $13(0 \cdot 2)$ & $33(0 \cdot 4)$ & $61(0 \cdot 8)$ \\
\hline 1998 & $279(3 \cdot 0)$ & $171(2 \cdot 1)$ & $16(0 \cdot 3)$ & $11(0 \cdot 1)$ & $56(0 \cdot 7)$ \\
\hline 1999 & $281(3 \cdot 1)$ & $154(1 \cdot 8)$ & $10(0 \cdot 2)$ & $18(0 \cdot 2)$ & $40(0 \cdot 5)$ \\
\hline 2000 & $281(3 \cdot 0)$ & $146(1 \cdot 8)$ & $18(0 \cdot 3)$ & $18(0 \cdot 2)$ & $41(0 \cdot 6)$ \\
\hline 2001 & $258(2 \cdot 7)$ & $123(1.5)$ & $12(0 \cdot 2)$ & $14(0 \cdot 2)$ & $55(0 \cdot 7)$ \\
\hline 2002 & $264(2 \cdot 7)$ & $159(1 \cdot 8)$ & $7(0 \cdot 1)$ & $24(0 \cdot 3)$ & $30(0 \cdot 4)$ \\
\hline 2003 & $254(2 \cdot 7)$ & $175(1 \cdot 8)$ & $10(0 \cdot 2)$ & $29(0 \cdot 3)$ & $28(0 \cdot 4)$ \\
\hline 2004 & $230(2 \cdot 4)$ & $176(1 \cdot 9)$ & $6(0 \cdot 1)$ & $27(0 \cdot 3)$ & $26(0 \cdot 4)$ \\
\hline 2005 & $227(2 \cdot 7)$ & $169(1 \cdot 9)$ & $15(0 \cdot 2)$ & $40(0 \cdot 4)$ & $25(0 \cdot 3)$ \\
\hline 2006 & $184(1 \cdot 9)$ & $120(1 \cdot 3)$ & $9(0 \cdot 1)$ & $52(0 \cdot 5)$ & $25(0 \cdot 3)$ \\
\hline 2007 & $168(1 \cdot 7)$ & $111(1 \cdot 1)$ & $10(0 \cdot 1)$ & $36(0 \cdot 4)$ & $14(0 \cdot 2)$ \\
\hline 2008 & $137(1 \cdot 4)$ & $116(1 \cdot 2)$ & $21(0 \cdot 2)$ & $50(0 \cdot 5)$ & $16(0 \cdot 2)$ \\
\hline 2009 & $134(1 \cdot 3)$ & $113(1 \cdot 1)$ & $19(0 \cdot 2)$ & $44(0 \cdot 5)$ & $31(0 \cdot 4)$ \\
\hline 2010 & $137(1 \cdot 4)$ & $148(1 \cdot 5)$ & $33(0 \cdot 3)$ & $44(0 \cdot 5)$ & $34(0 \cdot 5)$ \\
\hline 2011 & $126(1 \cdot 2)$ & $146(1 \cdot 4)$ & $53(0 \cdot 5)$ & $30(0 \cdot 3)$ & $35(0 \cdot 5)$ \\
\hline 2012 & $128(1 \cdot 2)$ & $148(1 \cdot 4)$ & $72(0 \cdot 6)$ & $42(0 \cdot 4)$ & $23(0 \cdot 3)$ \\
\hline 2013 & $110(1 \cdot 1)$ & $196(1 \cdot 8)$ & $114(0 \cdot 9)$ & $44(0 \cdot 4)$ & $28(0 \cdot 4)$ \\
\hline 2014 & $87(0 \cdot 9)$ & $203(1.9)$ & $136(1 \cdot 1)$ & $41(0 \cdot 4)$ & $12(0 \cdot 2)$ \\
\hline Overall & $5600(2 \cdot 5)$ & $3604(1 \cdot 7)$ & $842(0 \cdot 4)$ & $685(0 \cdot 3)$ & $602(0 \cdot 3)$ \\
\hline
\end{tabular}

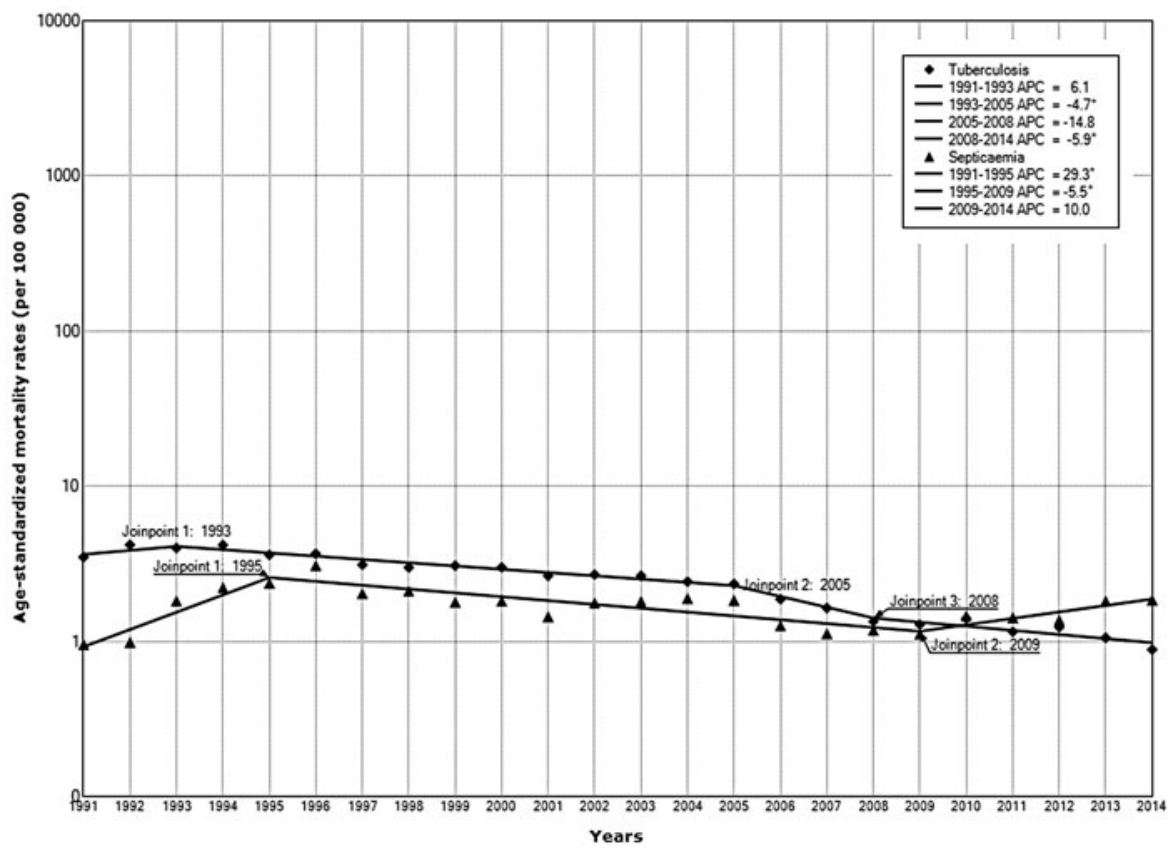

Fig. 4. Mortality from tuberculosis and septicaemia in Serbia, 1991-2014: a joinpoint regression analysis (using logarithmic scale). Tuberculosis (3 joinpoints) $v s$. septicaemia ( 2 joinpoints). * Statistically significant trend; APC, annual percent change. 
Table 4. Joinpoint regression analysis: trends* in age-specific tuberculosis and septicaemia mortality rates, men and women in Serbia, 1991-2014

\begin{tabular}{|c|c|c|c|c|}
\hline \multirow[b]{2}{*}{ Age, years $\dagger$} & \multicolumn{2}{|l|}{ Tuberculosis } & \multicolumn{2}{|l|}{ Septicaemia } \\
\hline & Period & APC $(95 \% \mathrm{CI})$ & Period & $\mathrm{APC}(95 \% \mathrm{CI})$ \\
\hline \multicolumn{5}{|l|}{ Men } \\
\hline \multirow[t]{4}{*}{$20-49$} & 1991-2014 & $-5 \cdot 9 *(-7 \cdot 2$ to $-4 \cdot 6)$ & 1991-1995 & $55 \cdot 6 *(21 \cdot 5$ to $99 \cdot 2)$ \\
\hline & & & 1995-2010 & $-11 \cdot 0 *(-14 \cdot 2$ to $-7 \cdot 7)$ \\
\hline & & & 2010-2014 & $14 \cdot 8(-10 \cdot 4$ to $47 \cdot 0)$ \\
\hline & & & Full period & $-4 \cdot 2 *(-7 \cdot 1$ to $-1 \cdot 1)$ \\
\hline \multirow[t]{3}{*}{$50-64$} & 1991-2004 & $-3 \cdot 0 *(-5 \cdot 6$ to $-0 \cdot 3)$ & 1991-1996 & $25 \cdot 7 *(4 \cdot 4$ to $51 \cdot 3)$ \\
\hline & 2004-2014 & $-11 \cdot 4 *(-14.9$ to $-7 \cdot 7)$ & 1996-2014 & $-1 \cdot 4(-4 \cdot 0$ to $1 \cdot 2)$ \\
\hline & Full period $t$ & $-6 \cdot 5^{*}(-7 \cdot 8$ to $-5 \cdot 1)$ & Full period & $1 \cdot 8(-0.5$ to $4 \cdot 1)$ \\
\hline \multirow[t]{6}{*}{$\geqslant 65$} & $1991-1994$ & $11 \cdot 7(-2 \cdot 1$ to $27 \cdot 4)$ & 1991-2004 & $9 \cdot 4 *(4 \cdot 6$ to $14 \cdot 3)$ \\
\hline & 1994-2005 & $-5 \cdot 5^{*}(-7 \cdot 4$ to $-3 \cdot 5)$ & 2004-2008 & $-17 \cdot 5(-46 \cdot 0$ to $26 \cdot 0)$ \\
\hline & 2005-2009 & $-15 \cdot 8 *(-26 \cdot 2$ to $-3 \cdot 9)$ & 2008-2014 & $19 \cdot 1 *(3 \cdot 1$ to $37 \cdot 3)$ \\
\hline & 2009-2012 & $7 \cdot 0(-17 \cdot 8$ to $39 \cdot 3)$ & Full period & $+4 \cdot 2 *(2 \cdot 0$ to $6 \cdot 4)$ \\
\hline & 2012-2014 & $-26 \cdot 9 *(-43 \cdot 8$ to $-4 \cdot 8)$ & & \\
\hline & Full period & $-6 \cdot 4 *(-7 \cdot 6$ to $-5 \cdot 2)$ & & \\
\hline \multirow[t]{6}{*}{ All men } & 1991-1993 & $9 \cdot 2(-5 \cdot 1$ to $25 \cdot 7)$ & 1991-1995 & $29 \cdot 9 *(17 \cdot 1$ to $44 \cdot 2)$ \\
\hline & 1993-2005 & $-4 \cdot 4 *(-5 \cdot 3$ to $-3 \cdot 5)$ & 1995-2001 & $-7 \cdot 3 *(-13 \cdot 9$ to $-0 \cdot 2)$ \\
\hline & 2005-2008 & $-18 \cdot 0 *(-28 \cdot 8$ to $-5 \cdot 6)$ & 2001-2004 & $6 \cdot 8(-23 \cdot 1$ to $48 \cdot 5)$ \\
\hline & 2008-2012 & $-2 \cdot 2(-8 \cdot 9$ to $4 \cdot 9)$ & 2004-2008 & $-16 \cdot 3 *(-29 \cdot 0$ to $-1 \cdot 3)$ \\
\hline & 2012-2014 & $-18 \cdot 0 *(-28 \cdot 7$ to $-5 \cdot 6)$ & 2008-2014 & $11 \cdot 2 *(5 \cdot 1$ to $17 \cdot 5)$ \\
\hline & Full period & $-6 \cdot 5^{*}(-7 \cdot 4$ to $-5 \cdot 6)$ & Full period & $-0.9(-2 \cdot 7$ to 0.9$)$ \\
\hline \multicolumn{5}{|l|}{ Women } \\
\hline $20-49$ & 1991-2014 & $-5 \cdot 9 *(-9 \cdot 2$ to $-2 \cdot 5)$ & 1991-2014 & $-5 \cdot 5 *(-8 \cdot 5$ to $-2 \cdot 5)$ \\
\hline \multirow[t]{3}{*}{$50-64$} & 1991-2014 & $-8 \cdot 2 *(-10 \cdot 7$ to $-5 \cdot 7)$ & 1991-1996 & $30 \cdot 2 *(8 \cdot 2$ to $56 \cdot 7)$ \\
\hline & & & 1996-2014 & $-1.9(-4.5$ to 0.7$)$ \\
\hline & & & Full period & $+1.8(-0.9$ to $4 \cdot 6)$ \\
\hline$\geqslant 65$ & 1991-2014 & $-5 \cdot 1 *(-6 \cdot 2$ to $-3 \cdot 9)$ & 1991-2014 & $+4 \cdot 6 *(2 \cdot 9$ to $6 \cdot 2)$ \\
\hline All women & 1991-2014 & $-6 \cdot 0 *(-6 \cdot 8$ to $-5 \cdot 1)$ & 1991-2014 & $-0 \cdot 8(-2 \cdot 7$ to $1 \cdot 3)$ \\
\hline
\end{tabular}

APC, Annual percent change; CI, confidence interval.

* Statistically significant trend.

$\dagger$ Joinpoint results are not shown for age subgroups $<20$ years, because $<10$ cases of tuberculosis/septicaemia deaths occurred in each of the decennium in any year.

$\$$ For full period average APC presented.

were reported in Ukraine $(45 \cdot 3 / 100000$ persons) and the lowest rates in Finland (4.2/100 000 persons). In women, the lowest rate was also reported in Finland but a similar rate was also reported in Poland ( 2.5/ 100000 persons for both), while the highest rates were reported in Israel and Ukraine (20.0 and 14.6/100 000 persons, respectively). With a rate of $4 \cdot 4 / 100000$ persons in 2012, Serbia ranked among the countries with the lowest mortality of infectious diseases.

The 20th century saw an overall reduction in mortality of infectious diseases worldwide [2-7]. However, during 1991-1994 and 2009-2014, Serbia saw increases in infectious disease mortality. The possible explanations for the unfavourable trend during these periods include the devastating effects of civil wars, which occurred in the former Yugoslavia in 1991-1995, the economic and political sanctions imposed by the United Nations in 1992-1995, the hyperinflation of the national currency in 1993, which was followed by the influx of more than half a million refugees that required care and strained the national economy, an overall disrupted healthcare system, and the global financial crisis that began in 2007 [19].

In Serbia, the increasing mortality trend affects the male population more than the female population, especially for males aged $\geqslant 65$ years; this trend contrasts the favourable patterns that have been observed in European Union countries [18]. However, in contrast to the relatively decreasing patterns in women in Serbia, women in the European Union countries show an increasing trend, especially those aged $\geqslant 65$ years. The precise mechanisms that might account 
for these age and sex differences in mortality from infectious diseases remain unknown, but potential factors include socioeconomic, anatomical and behavioural aspects that may represent differences in exposure to pathogens, and biological aspects that may represent differences in susceptibility and response to infectious diseases (i.e. genetic and hormonal factors that may modulate immune responses against pathogens, susceptibility or disease progression, and responsiveness to treatment and vaccines) or that may lead to differences in resistance to severe infection $[20,21]$.

Unfavourable trends in mortality from infectious diseases in men in Serbia could be attributed primarily to mortality from septicaemia. The increased rates of deaths from septicaemia in Serbia might have been a consequence of unfavourable circumstances specific to the country's socio-political fluctuations during the observed period, namely the marked decline in the general standard of living, the unsatisfactory quality of health services (including a lack of vaccines, drugs, medical equipment, a large increase in wounded nationals and refugees requiring medical and social care, decreasing hospitalization rates, particularly for people aged $\geqslant 60$ years, and irresponsible antibiotic use), social disintegration, ageing of the population that accompanies immunodeficiency, as well as other factors [19]. The relatively favourable trend in mortality from tuberculosis, on the other hand, may be attributed to the implementation of mass preventive programmes and improvements in tuberculosis treatment in Serbia [14].

An obvious declining trend was observed for overall mortality in Serbia during the entire study period (1991-2014), but stratification analysis by age and sex revealed different patterns within the trend of infectious disease mortality. A significant increasing trend in mortality from infectious diseases was observed in men aged 20-49 years during 1991-1998 and men aged $\geqslant 65$ years (the oldest group) during 2009-2014. A decline in mortality from tuberculosis was observed in all age groups for both sexes, unlike the increasing trend in mortality from septicaemia that occurred in the last decade of the 20th century in all age groups in men and in women aged $>50$ years. Two joinpoints were noticed for men only: in 1995 when a significant increasing trend in septicaemia mortality was followed by a significant decrease, and in 2008 when a significant decreasing trend in septicaemia mortality was followed by a significant increase. For women, the mortality trend for septicaemia showed no significant changes over the entire study period. Significant changes in temporal trends of infectious disease mortality, especially for men, did not correspond to the temporal trends found for overall mortality in Serbia; this apparent discrepancy could be explained, at least partly, by the presence of a small percentage of infectious diseases in overall mortality and domination of non-communicable diseases, which themselves have shown an increasing trend in the observed period [22-24]. Of course, this increased mortality trend for infectious diseases could be merely a coincidence, although it can be surmised rather that the change in frequency of infectious diseases would be expected to occur within such a short period of time, unlike that for chronic noncommunicable diseases, which are characterized by a significantly longer duration of pathogenesis. In times of crisis and wars, increasing trends in infectious diseases are commonplace and have been reported for many countries [25-31]. While the favourable mortality trend that was found in our study for tuberculosis corresponds to the implementation of preventive measures and therapy procedures [32], similar countrywide strategies for the prevention and treatment of septicaemia were very limited [19, 33]. According to our results, it can be concluded that the change in mortality trend from infectious diseases was caused by changes in mortality in men aged $>20$ years, most likely due to septicaemia.

Greater responsibility and stress may be placed on men in times of wars and economic crisis and this could be an explanation for the more unfavourable mortality from infectious diseases found in men than in women in Serbia $[34,35]$. The period in which Serbia was subject to civil wars and United Nations sanctions (1992-1995) was followed by years marked by the collapse of the economy, deterioration of living conditions, brutal hyperinflation of the national currency, and collapse of the healthcare system, which included lack of medicines, vaccines and medical supplies [19, 33].

In the last decade of the 20th century, the former Yugoslavia was the scene of several wars that produced their own contingents of refugees that came to Serbia. Over the last 25 years, $\sim 650000$ refugees have traversed from the former Yugoslavia to reside in Serbia $[14,36]$. Over the past two decades, 140000 of these refugees have returned to their countries of origin and $\sim 50000$ persons migrated to third countries; however, the majority of the refugees have remained in Serbia and integrated into the social and economic fabric of the country. Additionally, nearly 300000 of the internally 
displaced persons (from Kosovo \& Metohia) live within Serbia [36]. Although the refugee population of Serbia has a somewhat higher percentage of elderly, it does not appear to differ significantly from the domicile population of Serbia, according to reported demographic characteristics. The vulnerability of the Serbian economy, which is still in transition, further deteriorated because of the current global economic crisis. Over the last two decades, the unemployment rate in Serbia was $20 \%$ for the domicile population and $33 \%$ in the refugee population [36]. Unfortunate$1 \mathrm{y}$, in Serbia there are no precise indicators available to determine the health status of refugees, which would otherwise enable comparisons of health status before, during, and after the war [37].

The disastrous consequences of epidemics recorded in relation to the history of warfare are well known throughout the world [27, 28]. In addition, impact of crises on infectious diseases has been evidenced by numerous studies in Greece, countries of the former Soviet Union and Eastern Europe, Cuba and South Africa [25, 38-40]. Since there is no mortality data available for the previous period, a study by Vlajinac and colleagues [13], that described the trend of declining mortality in the region of Central Serbia in the period 1973-1993, may provide insight since it could indicate the mortality pattern from infectious diseases during this period. Vlajinac and colleagues [13] showed that during the period 1987-1990, mortality from infectious diseases, for both men and women, was significantly higher than expected on the basis of the trend for the preceding period, and that there was a statistically significant departure from the preceding trend in men from the period between 1991 and 1993, with the main effect being in younger age groups. A few other case reports have suggested that newborns are among the most vulnerable groups regarding infectious diseases in the studied period [41, 42].

The declining trends in overall mortality in Serbia since 2000 may be attributable to a number of factors, including improvements in diagnostic and therapeutic technologies, re-establishment of a regular supply of drugs and vaccines, democratic changes, economic development, and general improvements in living conditions. The reported leading causes of death in Serbia (cancer, ischaemic heart disease, diabetes mellitus) have shown markedly increased trends for the period 1991-2010 [24]. Paradoxically, the declining trend in overall mortality in Serbia has coincided with the global economic crisis. A better understanding of modern public health, primary prevention programmes and implementation of preventive measures (e.g. tobacco and alcohol control, and disease screening) probably contributed to the decreasing overall mortality observed in Serbia.

Despite the declining trend in overall mortality, a better understanding of temporal trends in infectious disease mortality should shed some light on the areas for improvement in developing new and improved healthcare and disease prevention programmes.

\section{Strengths and limitations of the study}

This nationwide study is the first to examine the 24-year trends of mortality from infectious diseases in Serbia. Furthermore, the death registration system (i.e. the source of this study's data) provides uniform data for the entire geographical boundaries of the Serbian nation. Mortality data in Serbia was estimated in this study as medium quality, when assessed according to WHO criteria (completeness was $>90 \%$ and ill-defined codes appear on $<10 \%$ of registrations) [43]. The presented trends represent crucial knowledge for monitoring the epidemiological characteristics of infectious diseases that affect the entire Serbian nation, as well as for evaluation of the various preventive and therapeutic measures already in place.

However, several limitations are inherent to the study design and must be considered when interpreting the findings. We acknowledge that a longer study period may be better to more accurately assess mortality time-trends in Serbia, but there was no data available for this. In addition, the lack of data on deaths from infectious diseases specifically in the refugee population serves as a confounding factor in the analysis of infectious disease patterns in Serbia. Certainly, it is important to continue with efforts for assessing and improving the quality of mortality statistics in Serbia.

Mortality of infectious diseases significantly decreased during the last two decades in Serbia. However, the increased mortality trends in men, particularly elderly men, are worrisome. The data presented herein might be useful to improve control of infectious diseases in Serbia.

\section{ACKNOWLEDGEMENTS}

This work was carried out with no dedicated source of funding. 


\section{DECLARATION OF INTEREST}

The authors have no conflicts of interests to declare in relation to this study or publication of its findings.

\section{REFERENCES}

1. WHO. WHO methods and data sources for global causes of death 2000-2012. Global Health Estimates. Technical Paper WHO/HIS/HSI/GHE/2014·7. World Health Organization, 2014.

2. Centers for Disease Control and Prevention. Achievements in public health: control of infectious diseases. Morbidity and Mortality Weekly Report 1999; 48: 621-629.

3. Armstrong GL, Conn LA, Pinner RW. Trends in infectious disease mortality in the United States during the 20th century. Journal of the American Medical Association 1999; 281: 61-66.

4. Arkwright PD, David TJ. Past mortality from infectious diseases and current burden of allergic diseases in England and Wales. Epidemiology and Infection 2005; 133: 979-984.

5. Bi P, et al. Trends in mortality rates for infectious and parasitic diseases in Australia: 1907-1997. Internal Medicine Journal 2003; 33: 152-162.

6. Serraino $\mathrm{D}$, et al. Time trends in infectious disease mortality in Italy: 1969-1999. Epidemiologia e Prevenzione 2004; 28: 322-329.

7. López-Cuadrado T, et al. Trends in infectious disease mortality rates, Spain, 1980-2011. Emerging Infectious Diseases 2014; 20: 782-789.

8. National Institutes of Health (USA). Biological Sciences Curriculum Study. NIH Curriculum Supplement Series. Bethesda (MD): National Institutes of Health (USA), 2007. Understanding Emerging and Re-emerging Infectious Diseases.

9. Mackey TK, et al. Emerging and reemerging neglected tropical diseases: a review of key characteristics, risk factors, and the policy and innovation environment. Clinical Microbiology Reviews 2014; 27: 949-979.

10. Kazemnejad A, et al. Global epidemic trend of tuberculosis during 1990-2010: using segmented regression model. Journal of Research in Health Sciences 2014; 14: 115-121.

11. Bonovas S, Nikolopoulos G. High-burden epidemics in Greece in the era of economic crisis. Early signs of a public health tragedy. Journal of Preventive Medicine and Hygiene 2012; 53: 169-171.

12. Nikolopoulos GK, et al. National income inequality and declining GDP growth rates are associated with increases in HIV diagnoses among people who inject drugs in Europe: a panel data analysis. PLOS ONE 2015; 10: 0122367.

13. Vlajinac HD, et al. Infectious diseases mortality in central Serbia. Journal of Epidemiology and Community Health 1997; 51: 172-174.

14. Statistical Office of the Republic of Serbia. Demographic Yearbook in the Republic of Serbia, 1991-2014.
Belgrade: Statistical Office of the Republic of Serbia; 2015.

15. Kim HJ, et al. Permutation tests for joinpoint regression with applications to cancer rates. Statistics in Medicine 2000; 19: 335-351.

16. Clegg LX, et al. Estimating average annual per cent change in trend analysis. Statistics in Medicine 2009; 28: $3670-3682$.

17. Kim HJ, et al. Comparability of segmented line regression models. Biometrics 2004; 60: 1005-1014.

18. WHO. European health for all database. WHO Regional Office for Europe, Copenhagen, Denmark, 2016.

19. Kunitz SJ. The making and breaking of Yugoslavia and its impact on health. American Journal of Public Health 2004; 94: 1894-1904.

20. Beisel $\mathbf{C}$, et al. Sex differences in infectious diseases and their clinical consequences [in German]. Deutsche Medizinische Wochenschrift 2015; 140: 1385-1390.

21. van Lunzen J, Altfeld M. Sex differences in infectious diseases-common but neglected. Journal of Infectious Diseases 2014; 209: S79-80.

22. Ilic M, Ilic I. Malignant lymphatic and hematopoietic neoplasms mortality in Serbia, 1991-2010: a joinpoint regression analysis. PLoS ONE 2014; 9: e109379.

23. Ilic M, Ilic I. Prostate cancer mortality in Serbia, 19912010: a joinpoint regression analysis. Journal of Public Health (Oxford). Published online: 20 May 2015. doi:10.1093/pubmed/fdv064.

24. Ilic M, et al. Association of the consumption of common food groups and beverages with mortality from cancer, ischemic heart disease and diabetes mellitus in Serbia, 1991-2010; ecological study. BMJ Open 2016; 6: $\mathrm{e} 008742$

25. Gustafson $\mathbf{P}$, et al. Tuberculosis mortality during a civil war in Guinea-Bissau. Journal of the American Medical Association 2001; 286: 599-603.

26. Baez JE. Civil wars beyond their borders: the human capital and health consequences of hosting refugees, Journal of Development Economics 2011; 96: 391-408.

27. Sharara SL, Kanj SS. War and infectious diseases: challenges of the Syrian civil war. PLoS Pathogens 2014; 10: e1004438.

28. Alawieh A, et al. Revisiting leishmaniasis in the time of war: the Syrian conflict and the Lebanese outbreak. International Journal of Infectious Diseases 2014; 29: $115-119$

29. Khang YH. Two Koreas, war and health. International Journal of Epidemiology 2013; 42: 925-929.

30. Khaji A. Mortality of the Iranian ex-prisoners of war in Iraqi detention camps (1980-1990). Archives of Iranian Medicine 2009; 12: 140-144.

31. Centers for Disease Control and Prevention. Elevated mortality associated with armed conflict - Democratic Republic of Congo, 2002. Morbidity and Mortality Weekly Report 2003; 52: 469-471.

32. Pesut DP, et al. Tuberculosis incidence in elderly in Serbia: key trends in socioeconomic transition. Croatian Medical Journal 2008; 49: 807-812.

33. Black ME. Collapsing health care in Serbia and Montenegro. British Medical Journal 1993; 307: 1135-1137. 
34. Giefing-Kröll C, et al. How sex and age affect immune responses, susceptibility to infections, and response to vaccination. Aging Cell 2015; 14: 309-321.

35. Roelfs D, et al. War-related stress exposure and mortality: a meta-analysis. International Journal of Epidemiology 2010; 39: 1499-1509.

36. Lukic V. Two decades of refuge in Serbia: census of population, households and dwellings 2011 in the Republic of Serbia. Belgrade: Statistical Office of the Republic of Serbia, 2015.

37. Litvinjenko S. Migration and health [in Serbian]. Srpski Arhiv Celokupnog Lekarstva 1997; 125: 191-196.

38. Simou E, Koutsogeorgou E. Effects of the economic crisis on health and healthcare in Greece in the literature from 2009 to 2013: a systematic review. Health Policy 2014; 115: 111-119.
39. Garfield R, Santana S. The impact of the economic crisis and the US embargo on health in Cuba. American Journal of Public Health 1997; 87: 15-20.

40. Suhrcke M, et al. The impact of economic crises on communicable disease transmission and control: a systematic review of the evidence. PLoS ONE 2011; 6: e20724.

41. Ilic M, Obradovic S. Vaccine-associated paralytic poliomyelitis - case report. Japanese Journal of Infectious Diseases 2014; 67: 135-136.

42. Ilic M, et al. Neonatal tetanus: report of a case. Turkish Journal of Pediatrics 2010; 52: 404-408.

43. Mathers CD, et al. Counting the dead and what they died from: an assessement of the global statusof cause death data. Bulletin of the World Health Organization 2005; 83: 171-177. 